\title{
CLINICAL STUDY OF ENDOSCOPIC FINDINGS IN PATIENTS PRESENTING WITH UPPER GI SYMPTOMS
}

\author{
Udayaravi M. Patremane1, Venkatachalam Periyasamy²
}

${ }^{1}$ Assistant Professor, Department of General Surgery, Kerala Medical College and Hospital, Mangode, Palakkad, Kerala. 2Associate Professor, Department of General Surgery, Kerala Medical College and Hospital, Mangode, Palakkad, Kerala.

\section{ABSTRACT}

\section{BACKGROUND}

Fibreoptic endoscopy has become the reliable, quick and inexpensive modality of investigation. Upper Gastrointestinal disorders are on rise in today's era due to change in lifestyle, food and habits. Endoscopy has a great role in diagnosis of upper GI diseases, premalignant, malignant conditions and in therapeutic interventions.

The objective of this study is to study the findings of upper GI Endoscopy in patients presenting with upper GI symptoms in our centre and to establish the importance of endoscopy as a tool to diagnose these disorders.

\section{MATERIALS AND METHODS}

An observational study conducted in Department of General Surgery in Kerala Medical College and Hospital, Mangode, Palakkad from July 2015 to January 2017.

\section{RESULTS}

Total number of patients who underwent upper GI Endoscopy is 186, out of which 118 were males and 68 were females with age ranging from 19 to 83 years. Normal findings were seen in 81 patients and 105 patients had abnormal endoscopic finding. 52 patients had findings in oesophagus, 43 in stomach and 10 in duodenum.

\section{CONCLUSION}

Upper gastrointestinal disorder is more common in males. Endoscopic abnormal findings were in order of oesophagus, stomach and duodenum. Endoscopic diagnosis of upper GI disorders is vital in proper management of diseases and prevention of complication. Endoscopy plays an important role in screening, diagnosis and therapeutic tool.

\section{KEYWORDS}

Upper GI Endoscopy.

HOW TO CITE THIS ARTICLE: Patremane UM, Periyasamy V. Clinical study of endoscopic findings in patients presenting with upper GI symptoms. J. Evolution Med. Dent. Sci. 2017;6(94):6881-6884, DOI: 10.14260/jemds/2017/1491

\section{BACKGROUND}

Upper Gastrointestinal (UGI) symptoms are among the commonest complaints, for which patients seek medical attention with the annual prevalence of dyspepsia approximating 25\%.[1] Diseases associated with these symptoms are leading causes of morbidity and mortality globally. Peptic ulcer disease (PUD), gastro-oesophageal reflux disease (GERD) and cancers affect millions of people worldwide.[2] Endoscopy holds an important place in the diagnosis of UGI conditions by enabling visualisation, photography, ultrasonography and biopsying of suspicious lesions.[3] It gives a better diagnostic yield over radiology, particularly in the investigation of upper gastrointestinal bleeding, inflammatory conditions of the upper gastrointestinal tract like oesophagitis, gastritis and duodenitis as well as the diagnosis of Mallory-Weiss tears and vascular malformations. ${ }^{[4]}$

The symptoms of upper gastrointestinal diseases are common. ${ }^{[5,6]}$ Upper gastrointestinal endoscopy also known as Oesophagogastroduodenoscopy (EGD) provides an excellent

'Financial or Other Competing Interest': None.

Submission 16-10-2017, Peer Review 25-11-2017,

Acceptance 01-12-2017, Published 18-12-2017.

Corresponding Author:

Dr. Udayaravi M. Patremane,

Assistant Professor in General Surgery,

Kerala Medical College and Hospital,

Mangode, Palakkad, Kerala.

E-mail: udayaravimp999@gmail.com

DOI: $10.14260 /$ jemds/2017/1491 modality for evaluating the underlying pathologies by enabling the visual inspection of the mucosa of the upper gastrointestinal tract (oesophagus, stomach and duodenum). Standard diagnostic indications for EGD include: Evaluation of an upper abdominal symptom that persists despite an appropriate trial of therapy, upper abdominal symptoms associated with other symptoms or signs suggesting structural disease (e.g. anorexia, weight loss) or new-onset dyspepsia in a patient older than 50 years of age. Others are dysphagia, odynophagia, oesophageal reflux symptoms that persist or recur despite appropriate therapy, persistent vomiting of unknown cause, other diseases in which the presence of upper gastrointestinal pathology might modify other planned management (e.g. patients who have a history of ulcer or gastrointestinal bleeding who are scheduled for organ transplantation, long-term anticoagulant or nonsteroidal anti-inflammatory drug (NSAIDS) therapy for arthritis and those with cancer of the head and neck), familial adenomatous polyposis coli syndrome, suspected neoplastic lesions, peptic ulcer, upper gastrointestinal stricture or obstruction, gastrointestinal bleeding, caustic substance ingestion and evaluation of chronic diarrhoea.[7]

The epidemiological data on incidence and prevalence of gastric disorders showed wide variation among the different population.[8] The pattern of GI disorders is unevenly spread all over the world. Due to improved lifestyle, the incidence of upper gastric disorders has been declining in some part of the world.[9] However, the knowledge about Upper GI disorders in certain communities is still not sufficient to prepare the guidelines for preventive measures. 
The risk factors like smoking, alcohol, tobacco, food habits, drugs, physical or mental stress, foreign bodies and bacterial infections actively plays an important role in predisposition and progression of these disorders.[10,11]

The present study is a observational study carried out in Department of General Surgery, Kerala Medical College and Hospital with the primary aim to study incidence of various upper GI tract disorders in patients with the complaints of upper gastrointestinal disorders.

\section{MATERIALS AND METHODS}

This is an observational study conducted in Kerala Medical College Hospital, Mangode from July 2015 to Jan 2017. Upper gastrointestinal endoscopy was done in patients presented to surgical outpatient with upper GI symptoms like retrosternal burning sensation, dyspepsia, nausea, vomiting, haematemesis, regurgitation, belching, loss of weight and appetite.

The upper GI endoscopy was done using Olympus videoscope according to the standard procedures. All patients received intravenous Hyoscine and pharyngeal spray with $10 \%$ xylocaine topical application before the procedure. Patients were observed for about an hour after the procedure.

The upper GI findings of the patients who underwent the procedure was obtained and analysed. The findings of upper GI endoscopy were noted and the distribution of these various findings with respect to age and sex was studied.

\section{RESULTS}

In our study, 186 patients underwent upper GI endoscopy for different symptoms. It consisted of 118 males and 68 females ranging from 19 years to 83 years. Patient in the age group 31 to 40 had highest frequency of 53 patients (28.49\%) followed by 41 to 50 with 42 patients (22.58). It was least in age group under 20 years with 3 patients (1.6) in the age group. Age group of patients who underwent upper GI endoscopy is summarised in Table No. 1.

\begin{tabular}{|c|c|c|}
\hline Age Group & Number of Patients & Percentage \% \\
\hline $11-20$ & 3 & 1.6 \\
$21-30$ & 21 & 11.29 \\
$31-40$ & 53 & 28.49 \\
$41-50$ & 42 & 22.58 \\
$51-60$ & 37 & 19.89 \\
$61-70$ & 21 & 11.29 \\
71 and above & 09 & 4.83 \\
\hline Total & $\mathbf{1 8 6}$ & $\mathbf{1 0 0}$ \\
\hline \multicolumn{3}{|c|}{ Table 1. Age Distribution } \\
\hline
\end{tabular}

Among the patients who underwent upper GI endoscopy had male preponderance. Out of 186 patients, 118 (63.44\%) males were present and $68(36.55 \%)$ were female patients.

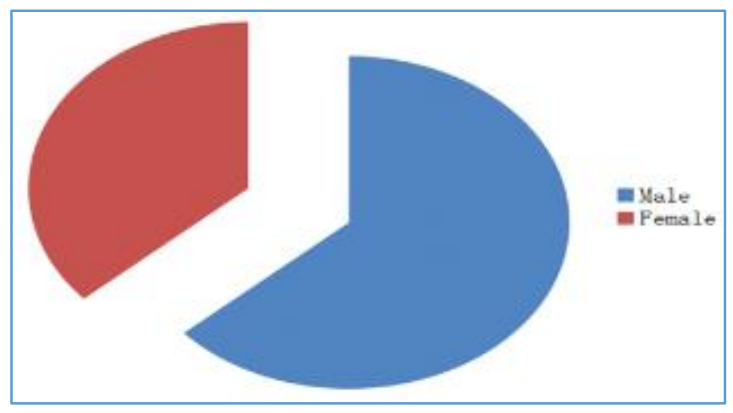

Sex Distribution
Patients undergoing upper GI endoscopy for different complaints had varied findings. Out of 186 patients, 81 (43.54\%) patients despite having upper GI symptoms had normal finding in the report. 105 (56.45\%) patients had abnormal findings in the upper GI scopy. Patients had varied symptoms from gastritis to gastric carcinoma.

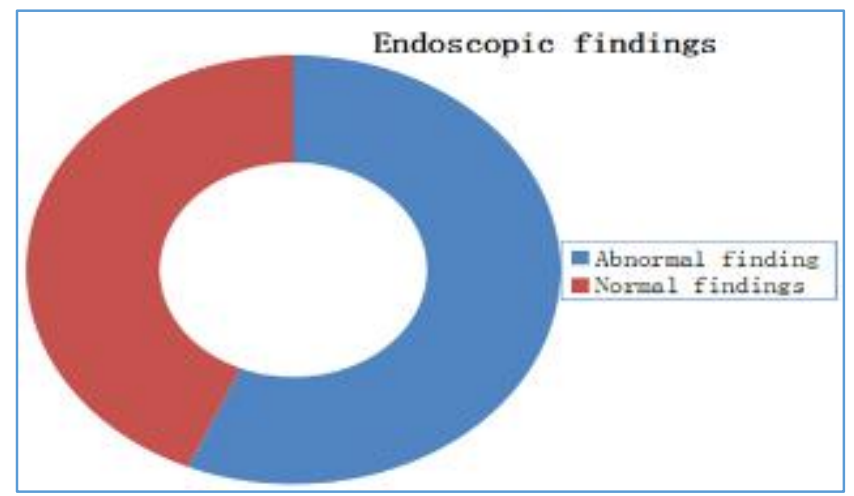

In our study patients having abnormal findings on upper GI endoscopy had lesions in order as follows: Oesophagus, stomach and duodenum. 52 patients had lesion in oesophagus, 43 had in stomach and 10 patients had the pathology in duodenum.

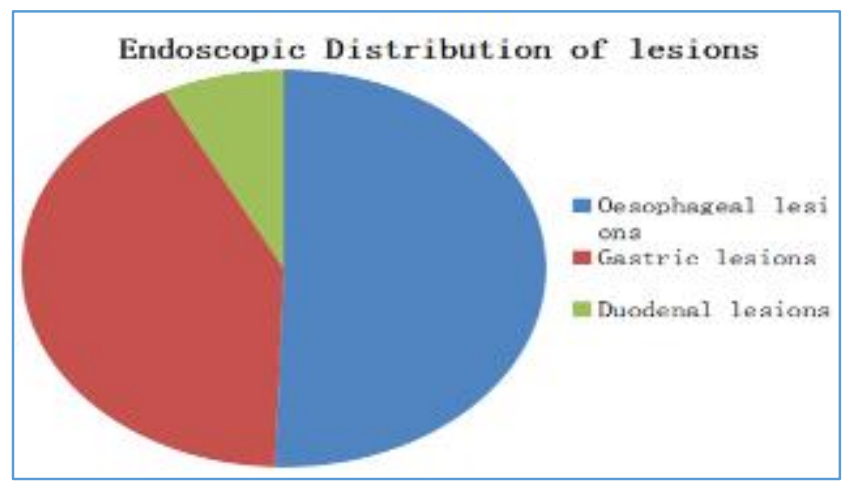

In our study population, the age group under 20 years were least in number and more number of patients with abnormal findings were there in age group of 40 - 60 years. Oesophageal lesion (27.95\%) is the most among the abnormal lesions; out of these oesophagitis is highest with 24 male patients and 8 females making 32 (17.2\%). In the abnormal findings in stomach gastritis, it is most common with total number of 37 (19.89\%) with 21 male and 16 female patients. Duodenitis is the most common duodenal lesion with 4 males and 3 females, totally 7 (4.8\%).

Gastritis is the most common abnormal finding in overall with 37 patients (19.89\%) followed by oesophagitis (17.2\%). Oesophageal CA, gastric carcinoma and duodenal ulcers are least common abnormal finding in the study population with $2(1.07 \%)$ patients diagnosed in each group.

Taking into account the sex distribution in abnormal lesions had male preponderance with 72 (38.7\%) being affected and 33 (17.7\%) were female patients. 


\begin{tabular}{|c|c|c|}
\hline $\begin{array}{c}\text { Clinical Findings on } \\
\text { Upper GI Endoscopy }\end{array}$ & $\begin{array}{c}\text { Male } \\
\text { (N-72) }\end{array}$ & $\begin{array}{c}\text { Female } \\
\text { (N-33) }\end{array}$ \\
\hline Oesophageal Candidiasis & 2 & 1 \\
Oesophageal Varices & 5 & 1 \\
GERD & 4 & 1 \\
Hiatus Hernia & 2 & 2 \\
Oesophagitis & 24 & 8 \\
Oesophageal Carcinoma & 2 & 0 \\
Gastritis & 21 & 16 \\
Gastric Ulcer & 3 & 1 \\
Gastric Carcinoma & 2 & 0 \\
Duodenitis & 4 & 3 \\
Duodenal Ulcer & 2 & 0 \\
\hline Table 2. Clinical Findings of Upper GI Endoscopy in \\
\multicolumn{2}{|c|}{ Males and Females } \\
\hline
\end{tabular}

\begin{tabular}{|c|c|c|c|c|}
\hline \multirow{2}{*}{$\begin{array}{c}\text { Clinical Findings of } \\
\text { Upper GI } \\
\text { Endoscopy }\end{array}$} & \multicolumn{4}{|c|}{ Age Distribution } \\
\hline & $<20$ & $20-40$ & $40-60$ & $>60$ \\
\hline $\begin{array}{l}\text { Oesophageal- } \\
\text { Candidiasis }\end{array}$ & 1 & 0 & 2 & 0 \\
\hline Oesophageal Varices & 0 & 2 & 4 & 0 \\
\hline GERD & 0 & 3 & 1 & 1 \\
\hline Hiatus Hernia & 1 & 2 & 1 & 0 \\
\hline Oesophagitis & 0 & 17 & 9 & 6 \\
\hline Oesophageal- & 0 & 0 & 1 & 1 \\
\hline Carcinoma & 1 & 13 & 20 & 4 \\
\hline Gastritis & 0 & 1 & 2 & 1 \\
\hline Gastric Ulcer & 0 & 1 & 1 & 0 \\
\hline Gastric Carcinoma & 0 & 2 & 3 & 2 \\
\hline $\begin{array}{c}\text { Duodenitis } \\
\text { Duodenal Ulcer }\end{array}$ & 0 & 1 & 0 & 1 \\
\hline Total & 3 & 42 & 44 & 16 \\
\hline
\end{tabular}

\section{DISCUSSION}

In this study, there were more males (63.44\%) than females $(36.55 \%)$. Ratio is similar to findings in majority of other countries, probably because UGI tract diseases are more prevalent in males.[2,4,12-14] Olokoba et al noticed a male-tofemale ratio of 1.05.[12] More male-to-female ratio was also reported by studies of Agbakwuru et al and Danbauchi et al in Zaria, North West Nigeria. Emmanuel Jeje et al also reported more male preponderance. A study conducted at Multan by Muhammad Inayatullah et al[15] shows more of male preponderance (50.6\% Males vs $49.4 \%$ Females). In the study conducted at Peshawar,[16] they had an almost equal number of males and females. However, Nkrumah et al in Saudi Arabia and Khurram et al in Pakistan[17,18] noticed more females as compared to males in their studies.

The age pattern is closely similar to those of other studies with very few presenting before the age of 20 years, peaking in fourth and fifth decade probably because UGI tract diseases are prevalent in the older population age group.[2,14] The reasons for sex and age differences are due to varying sample size, geographical location and time period of study carried out.

In our study, normal Endoscopy was reported in $43.54 \%$ $(n=81)$. Rate of negative Endoscopy $(43.54 \%)$ in our study was less as compared to reported rates in the study of Muhammad et al from Multan[10] and was higher as compared to negative Endoscopy $30 \%[15]$ as reported by Khalid Muhammad.[11] This observation was also reported by Shah et al.[19] Strict selection criteria required to reduce this rate will result in missing significant pathology in large number of patients.

In the present study, most of the patients presented with pain abdomen followed by vomiting. In the study by Ray and Pal, 9398 cases were studied and most of the patients presented with the similar complaints of pain abdomen.[20] Similarly, in a study of Kuwait series most of the patients presented with pain abdomen. In this study, most of the patients on upper GI endoscopy were found to have chronic gastritis and acute diffuse gastritis. The incidence of oesophagitis and gastritis was $17.2 \%$ and $19.89 \%$ respectively. In oesophagitis group, most of the patients were in the age group of 21 - 40 years. The incidence of gastritis was in the age group of $41-60$ years. This can be explained because of heavy alcohol and smoking consumption in the labourer group of people in this area. Gastric ulcer incidence was low about $2.15 \%$ compared to other studies by Al-Nakib and Al-Liddawi and Ray and $\mathrm{Pal}$, which was $5.9 \%$ and $4.9 \%$. In this rural population, incidence of gastric ulcer $(2.15 \%)$ and duodenal ulcer $(1.07 \%)$ was very low and seen in elderly age group people. This may be attributed to the widespread use of proton pump inhibitors in people, as PPI are coprescribed with NSAIDs; and antiplatelet agents are used for cardiovascular, cerebrovascular and rheumatological diseases. Also, the PPI are available easily over-the-counter without cost.

Oesophageal candidiasis in the present study had incidence of $1.61 \%$. It was seen more commonly among the male of the age group 41 - 60 years. Among the affected individuals, only 1 of them was seropositive for HIV. Candidiasis also affected other individuals (who were not seropositive for HIV). This may be attributed to the advanced age, diabetes mellitus, alcoholism, inhaled glucocorticoid use in asthmatics and acid suppressive therapy for patients with chronic gastritis.[8,9]

Hiatus hernia was found in $2.15 \%$ of the population, more common in age group of 21 - 40 years with equal male and female distribution. Oesophageal variceal disease affected about $3.22 \%$ with more commonly affected age group being 41 - 60 years. All affected patients were male and had alcoholic liver disease, except one female patient who had primary biliary cirrhosis.

\section{CONCLUSION}

Gastritis and oesophagitis are more common in the population. Based on the findings obtained from the study, further evaluation of the local population based on the symptoms can be formulated and change in the habits and lifestyle can be advised. Endoscopic diagnosis of upper GI disorders is vital in proper management of diseases and prevention of complication. Endoscopy plays an important role in screening, diagnosis and therapeutic tool.

\section{REFERENCES}

[1] Talley NJ, Vakil NB, Moayyedi P. American gastroenterological association technical review on the evaluation of dyspepsia. Gastroenterology 2005;129(5):1756-80.

[2] Agbakwuru EA, Fatusi AO, Ndububa DA, et al. Pattern and validity of clinical diagnosis of upper gastrointestinal diseases in south-west Nigeria. Afr Health Sci 2006;6(2):98-103. 
[3] Tytgat GN. Role of endoscopy and biopsy in the work up of dyspepsia. Gut 2002;50(Suppl 4):13- 6.

[4] Aduful H, Naaeder S, Darko $R$, et al. Upper gastrointestinal endoscopy at the Korle Bu teaching hospital, Accra, Ghana. Ghana Med J 2007;41(1):12-6.

[5] Heading RC. Prevalence of upper gastrointestinal symptoms in the general population: a systematic review. Scand J Gastroenterol 1999;231:3-8.

[6] Sobieraj DM, Coleman SM, Coleman CI. US prevalence of upper gastrointestinal symptoms: a systematic literature review. Am J Manag Care 2011;17(11):e44958.

[7] Early DS, Ben-Menachem T, Decker GA, et al. Appropriate use of GI endoscopy. Gastrointest Endosc 2012;75(6):1127-31.

[8] Loffeld RJ, Liberov B, Dekkers PE. The changing prevalence of upper gastrointestinal endoscopic diagnoses: a single-centre study. Neth J Med 2012;70(5):222-6.

[9] Miwa H. Life style in persons with functional gastrointestinal disorders--large-scale internet survey of lifestyle in Japan. Neurogastroenterol Motil 2012;24(5):464-71.

[10] Gastrits: overview. http:/www.gastritis.com/2007,http://pubmed.com

[11] Bode C, Bode JC. Alcohol's role in gastrointestinal tract disorders. Alcohol Health Res World 1997;21(1):7683.
[12] Olokoba AB, Bojuwoye BJ. Indications for oesophagogastroduodenoscopy in Ilorin, Nigeria--a 30 month review. Niger J Clin Pract 2010;13(3):260-3.

[13] Malu AO, Wali SS, Kazmi R, et al. Upper gastrointestinal endoscopy in Zaria, northern Nigeria. West Afr J Med 1990;9(4):279-84.

[14] Danbauchi SS, Keshinro IB, Abdu-Gusau K. Fifteen years of upper gastrointestinal endoscopy in Zaria (1978 - 1993). Afr J Med Sci 1999;28(1-2):87-90.

[15] Inayatullah M, Nazish Z, Akhtar MS, et al. Dyspepsia and upper gastrointestinal endoscopy. Professional Med J 2008;15(1);143-147.

[16] Mahmood K, Saeedi MI, Mohammad R, et al. Upper gastrointestinal endoscopic findings in patients with dyspepsia. JPMI 2006;20(1):70-73.

[17] Nkrumah KN. Endoscopic evaluation of upper abdominal symptoms in adult patients, Saudi AramcoAi Hasa Health Center, Saudi Arabia. West African Journal of Medicine 2002;21(1):1-4.

[18] Khurram M, Khaar HT, Hasan Z, et al. A 12 years audit of upper gastrointestinal endoscopic procedures. J Coll Physicians Surg Pak 2003;13(6):321-4.

[19] Shah NH, Shah MS, Khan I, et al. An audit of diagnostic upper GI endoscopy and comparison of booked versus open access cases. JCPSP 1999;9(4);174.

[20] Ray G, Pal S. Trends in endodiagnosis of upper gastrointestinal diseases at a referral railway hospital. J Dig Endosc 2011;2(4):213-9. 